\title{
IDÉ|AS
}

\section{Dilema: administrar com ou contra preços}

Floriano Freitas Filho (

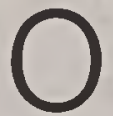

s preços não fazem parte da infra-estrutura de uma economia, mas são os melhores e mais simples indicadores da inflaçào. Nesse sentido, têm a mesma propriedade do termômetro para o médico, ao acusar pelas temperaturas altas o estado febril, a possivel infecção.

Nāo se sabe de médicos que tenham congelado seus termómetros, a fim de evitar a febre e eliminar a infecção de seus pacientes. Mas sabese, através dos séculos, de muitos governantes que congelaram preços, na tentativa de evitar ou controlar a inflaçāo.

Diocleciano, imperador romano (284 d.C. a 305 d.C.), a fim de debelar a inflaçào que assolava o imperio, determinou o controle de preços. Fez circular um edito ( 301 d.C.), que estabelecia o preço máximo de cada serviço, de cada objeto de troca. A penalidade por comprar ou vender acima do estabelecido era era a morte ou o exilio.(1)

Embora muitos tenham perdido a vida, tornou-se absolutamente necessário revogar a lei. Compreendeuse que havia algo mais, além da suposta causa de todos os males: "a ganância dos comerciantes".(2)

Em 1748 é publicado um dos mais extraordinários contos de Voltaire: "O Mundo Como Está - Visão de Babuc Escrita por Ele Próprio".

Ituriel, um dos gênios que presidem os impérios do mundo, desce certa manhã à morado do cita Babuc, à margem do Oxus, e diz-lhe: "- Babuc, as loucuras e excessos dos persas atrairam nossa cólera; reuniuse ontem uma assembléia dos gé-

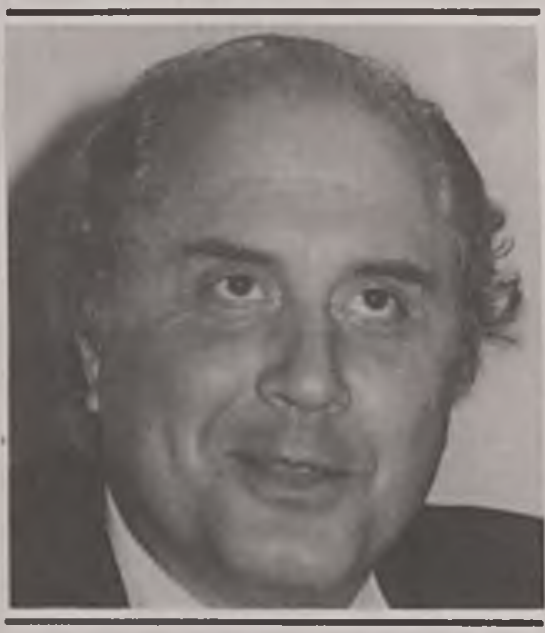

nios da Alta Ásia para decidir se devia castigar Perseepolis ou destruila. Vai a esta cidade, examina tudo; conta-me fielmente o que vires; e eu resolverei, conforme teu relato, corrigir a cidade ou exterminá-la."

Babuc, no cumprimento da misdores de magnificas bagatelas. Escolheu o que lhe agradou, pagando muito mais do que valia. Ao saber-se enganado, Babuc inscreveu nas suas tabuinhas o nome do negociante, para ndicá-lo a Ituriel no dia da puniçảo da cidade. Enquanto escrevia, bateramlhe à porta: era o proprio negociante que vinha trazer-lhe a bolsa que ele havia esquecido sobre o balcão.

Antonio, Babuc perguntou: "- Como se explica que o senhor se mostre tảo fiel e generoso, quando não teve vergonha de vender-me bugigangas quatro vezes acima de seu valor?" são, foi ao estabelecimento de vende-

(*)Professor do Departamento de Administração da Universidade de Brasillia.
Ao que lhe respondeu o comerciante: " - Não há nesta cidade nenhum negociante mais ou menos conhecido que nảo viesse devolverthe a bolsa; mas muito o enganaram, dizendo-lhe que eu the vendera artigos quatro vezes mais caro de que valiam: vendi-os por dez vezes mais. $\mathrm{E}$ tanto isto é verdade que, se daqui a um mès o senhor quiser revendè-los, não obterá nem essa décima parte. Mas nada mais justo: é a fantasia dos homens que dá preço a essas coisas frivolas; é essa fantasia que faz viver cem operários que eu emprego, é ela que me dá uma bela casa, um carro cómodo, cavalos, é ela que anima a indústria, que mantém o gosto, a circulação e a abundância. Ás nações vizinhas vendo eu essas bagatelas muito mais caro que ao senhor, e assim sou útil ao império."

"Babuc, d spois de haver cismado um pouco, riscou-o das suas tabuinhas."(3)

Administrar com ou contra os preços?

O imperador Septimio Severo (193/211 D.C.) combateu a inflação desvalorizando a moeda e aumentando os impostos. (4) Dioclesiano impós o controle de preços e procurou fixar o camponés no campo. Constantino (306/337 d.C.) "resolveu" o problema instituindo o estado totalitário.

Nenhuma dessas medidas, no entanto, freou a inflação em Roma. A mesma quantidade de trigo que custava 0,75 tetradrachmas em $100 \mathrm{~d}$.C., passou a custar $21 / 2 \mathrm{em}$ 200 d.C., $50 \mathrm{em} 270$ d.C., $2.500 \mathrm{em}$ 314 d.C., 21.000 em 334 d.C. e 500.000 em 344 d.C.(5).

A história nos fornece inúmeros exemplos e experiências análogas, sob circunståncias diversas -- e a inflaçào sempre prevaleceu. 


\section{IDÉIAS}

Na Roma antiga, a perda seqüente das possessōes romanas, pela decadència do império, reduziu a oferta de bens. Roma pouco produzia do que consumia. A inflaçāo crônica foi inevitável, assim como o retorno do homem ao campo e mil anos de feudalismo.

No mundo contemporâneo, as causas da inflação são bem diversas e complexas. É possivel decompó-las em elementos os mais sofisticados, a maioria dos quais mensuráveis. Modelos econométricos se sucedem, na tentativa de racionalizar causas, efeitos, soluçōes.

Mas, por força de tanta racionalização, a causa principal da inflaçāo parece estar sendo paulatinamente relegada a segundo plano - a civilização moderna; as exigèncias naturais da sociedade contemporânea.

Durante milènios, o homem e sua familia, numa organizacão nòmade e tribal, subsistiu da caça. Produção e consumo se confundiam, sem intermediaçōes.

O mesmo pode-se dizer da organização das sociedades rurais. A relação direta produção-consumo prevaleceu por outros milènios, muito embora já se esboçasse a intermediação e um incipiente sistema de preços. Dificilmente o ser humano sobreviveria à impossibilidade de participar diretamente da produçào, por si ou por aquele de quem dependesse.

Até meados do século passado prevaleceu a forma de organizaçào societária rural. As maiores concentraçōes urbanas do mundo não atingiram um milhão de habitantes.

A terra fora, até então, o fator estratégico básico. Conservá-la em familia era um imperativo. Dai valores fundamentais dessa forma de vida: a propriedade, a castidade feminina, o matrimónio monogâmico, o primogènito, a herança, o tradicionalismo, a pouca mobilidade social

Com o advento da industrializaçào, as concentraçōes urbanas multiplicaram-se e hipertrofiaram-se. Em apenas cem anos, as sociedades sofreram expressivas transfiguraçōes, renovando valores, rompendo tradicỏes.

$\mathrm{Na}$ moderna civilizaçāo capitalista prevalece o individuo, desde na moradia (cada qual quer a sua), até nos mais variados itens de consumo ( seu carro, seu televisor, seu vestuário, seu eletrodoméstico...). Mas ninguem, individual ou familiarmente, produz qualquer coisa disso e de tudo

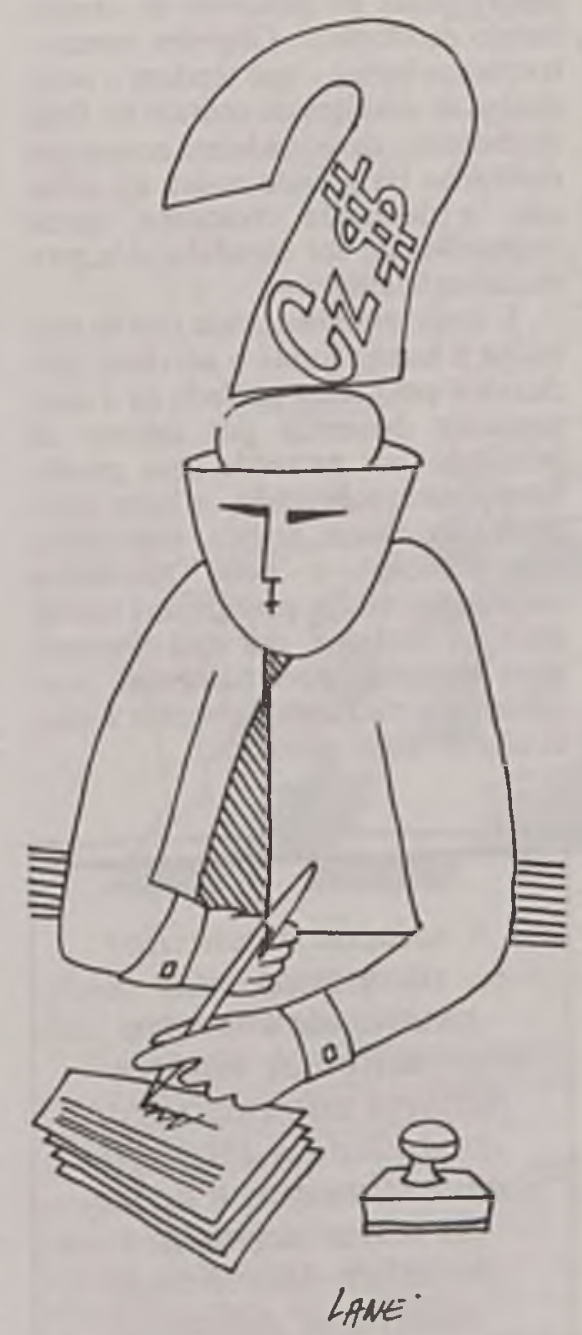

o mais que lhe é fartamente ofertado: Bem pelo contrário: o consumidor distancia-se cada vez mais do produtor.

Não hả o imperativo de se produzir o que se quer, como na organização societária rural. Há, apenas, a exigéncia de se estar engajado no processo produtivo com a força de seu trabalho ou cedendo fatores outros de produção, sob sua propriedade. $\mathrm{O}$ valor supremo é a riqueza individual, centrada na renda pessoal ou familiar (o somatório de salários, juros, lucros, aluguéis...).

Mas a capacidade de compra nảo se resume à riqueza individual ou familiar. E imposta pelo sistema de preços, de todos os preços.

O preço passa a ser o grande fator de seleçăo dentre os que pretendem adquirir mercadorias e serviços, ajustando produçào e consumo, nas economias de livre mercado. Compra quem puder pagar o preço dos bens ofertados, na força dos preços pagos pelos fatores de produção que detém (da renda pessoal). Nesse sentido, congelar preços é inviabilizar essa seleçà, é instituir o caos.

Verificou-se, entretanto, que os mecanismos de ajuste, via preços, não são tão simples e de efeitos imediatos.

Nas últimas décadas, o pensamento econômico deu ènfase a estudos sobre os mecanismos de ajuste, via preços, nos mercados concorrenciais imperfeitos (concorrència monopolistica, oligopólio, monopólio). Nenhum desses estudos, entretanto, rejeitou o mecanismo em si, ou dotou a economia de mercado de um sistema seletivo alternativo, justo e viável.

Em outras palavras, nas economias de mercado, seja qual for o caminho de solução idealizado, o problema será sempre o mesmo: como tantos, que individualmente produzem tão pouco, poderào consumir o que desejam do muito que thes é ofertado? Se os preços não forem o fator de seleção, quem o será? $O$ governo? - sob que critérios?

A ascensão dos preços, a inflação, seja qual for sua causa, é indicativa de excesso de demanda em algum setor da economia ou, o que dá no mesmo, caréncia de oferta. Alguém, mais tarde ou mais cedo, deixará de comprar este ou aquele bem (materiaprima, intermediário ou final), por não ter a capacidade de pagar seu preço. $\mathrm{O}$ preço seletivo determinará, em última instância, quem adquirirá o 


\section{IDÉIAS}

quê e quanto. O raciocinio se completa se considerarmos salários, juros, lucro, aluguéis como preços dos fatores de produção. Se os preços estiverem livres, são eles os melhores indicadores das distorçōes na economia, dos focos inflacionários. Trabalhar contra eles, só numa economia planificada, de decisões econômicas centralizadas ou num sistema utópi$\mathrm{co}$, governado por semideuses, onipresentes e oniscientes.

As causas da inflação são as mesmas que conduzem à elevação dos preços, já que um fenómeno comporta o outro. Esse óbvio é por vezes esquecido. Em outras palavras, debelar a inflação é debelar as causas que levam à elevação dos preços. Dai qualquer argumentaçào que envolva o combate á inflacáo dever considerar a estabilidade de preços como um fim (causa final) e não como um meio (causa material).

Hà, pois, que se administrar a inflação com os preços, nào contra os preços, pelas causas da elevação destes e não pelo efeito - a elevação $\mathrm{cm}$ si, mero indicador da propria inflaçăo. Seria como o médico que, ao detectar a infecção, acusada pela alta temperatura indicada no termómetro. se preocupasse em debelar as causas da mesma, usando o termòmetro como aferidor de sua regressão.

Quais as causas da inflação, da elevação dos preços?

Que medidas conduzem à estabilização dos preços, debelam a inflação?

No modelo clássico de desenvolvimento, no mundo capitalista, os excedentes agricolas permitem o comercio e a gènese de servicos concentrados e localizados (burgos, vilas, cidades), com a seqüente industrialização. As concentraçoes urbanas surgem naturalmente, fruto de um processo de crescimento econòmico harmónico e equilibrado, com mecanismos de ajustes viáveis, via comportamento dos preços, ainda que através de conflitos de interesses e crises ciclicas bastante acentuadas.

O Brasil, assim como outros paises de economia periférica, desenvolveu-se na dependência das grandes potencias industriais do hemisferio norte, não seguindo o modelo clássico. O desenvolvimento deu-se por saltos, regionalmente diferenciado. Daí a geração de disparidades na distribuição da renda pessoal ou regional, a criação de bolsões de riqueza ao lado de bolsōes de po- breza, as conseqüentes e crescentes tensões sociais, os desequilibrios e as desarmonias no processo de crescimento económico. Grandes concentraçooes urbanas - que tendem a estar dentre as maiores do mundo no final do milènio-desencadeiam concausas derivadas da grande causa da inflação: a demanda crescente, quase impossivel de ser atendida pela produção existente.

E mais: essa demanda não se restringe a mercadorias e serviços produzidos pelo setor privado (e a conseqüente demanda por fatores de produção por parte de seus produtores) mas, sobretudo, a bens coletivos (segurança, justiça, transporte, comunicação) e bens meritórios (educação, saúde, previdência social, etc.) "produzidos" por uma onerosissima maquina governamental, concorrente e não complementar à produçảo do setor privado.

\begin{tabular}{|c|}
\hline A soluçào é conciliar \\
os opostos, mas \\
através de um novo \\
arquétipo de homem \\
puiblico: administrador \\
capacitado a interagir \\
conhecimentos e acôes \\
de vários segmentos \\
do saber, conciliando \\
exigências políticas \\
com outras de ordem \\
técnica. Possível? \\
\end{tabular}

As grandes disparidades regionais na distribuição de renda, e a necessidade politico-social de se acelerar a estirpação dos bolsōes de pobreza, forçam cada vez mais o crescimento descontrolado dessa maquina, dotando o Pais de estrutura de produção estatizada, ineficiente, desarmònica. dependente de recursos externos e, por tudo isso e muito mais, cronicamente onerosa e deficitaria. O setor privado herda dessa concorréncia uma crescente elevação de custos financeiros e de materiais, que deságuam em inflaçào.

Eliminar essas causas - um desafio gigantesco para estadistas (homens de decisão e de poucos sonhos) - é o único caminho para se estabilizar preços, debelar a inflação.

Nào será através de soluçōes pirotécnicas, assentadas em sonhos de uma noite de verão ou em delírios de algum politico bem intencionado, mas mal informado quanto à inexorabilidade das leis econômicas, que se chegará a esse objetivo.

A questão também não se resume à simplicidade de alguma postura existencial perante o problema (ou parte dele). Algo assim como posicionar duas escolas principais do pensamento político-filosófico: "o racionalismo evolucionista fundado na liberdade individual e na propriedade privada, que corresponde à sociedade aberta, em oposição ao racionalismo construtivista baseado no coletivismo e no estatismo, que corresponde à sociedade planificada totalitária."(6) Ou uma ou outra. Nem, muito menos, no diferençar economistas planificadores de economistas keynesianos matematicistas, ou de estruturalistas, ou de monetaristas de afinados ou de desafinados com a economia moderna de mercado. Rótulos, meros rótulos.

A questão é de administração. De gerencia de problemas. Como administrar realidade tão complexa como a que descrevemos em largos traços, segundo as tradições que nos são peculiares e que nos conduzem sempre à conciliação dos opostos?(7)

Como administrar a inexorabilidade das leis econômicas, a inexorabilidade dos direitos do cidadão, a inexorabilidade das pressōes dos anseios da sociedade contemporânea, a inexorabilidade da força de absorção dos valores que compóem o novo conceito de justiça social, e tantas outras inexorabilidades?

Tantas inexorabilidades dão espaço à negociação, à conciliação? É possivel administrar o desenvolvimento, o crescimento económico, com os preços e não contra os preços, priorizando a liberdade individual, garantindo a propriedade privada, com crescente ingerência do governo na economia, sem o estatismo da sociedade totalitária, sem o perigo de iludir o povo, no encobrir a dureza dos fatos, a frieza dos atos?

A experiência recente com os Planos Cruzados demonstra que a inflação brasileira é sobretudo decorrente de causas de ordem estrutural e não inercial (esta, mera conseqüència do administrar contra os preços). 
A pressão da demanda, característica da sociedade brasileira atual, decorre da elevada e crescente concentração urbana, assim como das distorçōes decorrentes de um desenvolvimento desarmônico. A incursão cada vez mais acentuada do Estado na Economia decorre de idênticas causas e, via de conseqüência, o crescimento contínuo dos gastos do governo, das dividas interna e externa, do déficit público, etc...

Estudo recente do brasilianista Raymond W. Goldsmith conclui que "durante todo o periodo compreendido entre 1850 e 1980 o aumento médio anual do nivel de preços, seja no atacado ou no varejo, ocorreu numa base de $10 \%$, nivel este que pode justificar a caracterizaçāo de uma inflação secular. ( $O$ aumento médio do nivel de preços nos Estados Unidos - medido pelo deflator do PNB - no mesmo periodo, foi ligeiramente inferior a $2 \%$ ). Nesse periodo houve grandes surtos inflacionários $(1853 / 1854 ; 1864 / 66 ; 1869$. 1874/78; 1889/94; 1915/24; $1942 / 66 ; 1974 / 1980)$, preços quase estáveis (1880/88; 1905/14; 1924/34) e até mesmo quedas de preços $(1861 / 63 ; 1870 / 71 ; 1879 / 80$; $1900 / 5 ; 1930 / 31) .(8)$

No Brasil, em decorrència das características históricas de sua sociedade, Governo e economia de mercado têm de conviver, sob inevitáveis confrontos.

A solução é a conciliação dos opostos, mas através de um novo arquétipo de homem público: o administrador - aquele capacitado a interagir conhecimentos e ações de vários segmentos do saber, conciliando exigèncias politicas com outras de ordem técnica.

Ao economista, a Economia - o estudo das causas e conseqüências da inexorabilidade de algumas leis econômicas; ao politico, a Politica - a arte de dirimir conflitos de interesses, de representar reivindicaçóes de grupos, defendendo e tutelando seus pontos de vista; ao jurista, o Direito, a Ordem; ao legislador, o ordenamento, e assim por diante.

Ao administrador, a Administraçào - $\mathrm{a}$ arte de compor os opostos via negociações, objetivando a conciliação, administrando com o sim e com o não, sob o eterno propósito de realizar metas factiveis, com eficiência, com eficácia. Acresça-se, ao administrador publico, uma profunda sensibilidade à justiça social, que

\section{IDÉIAS}

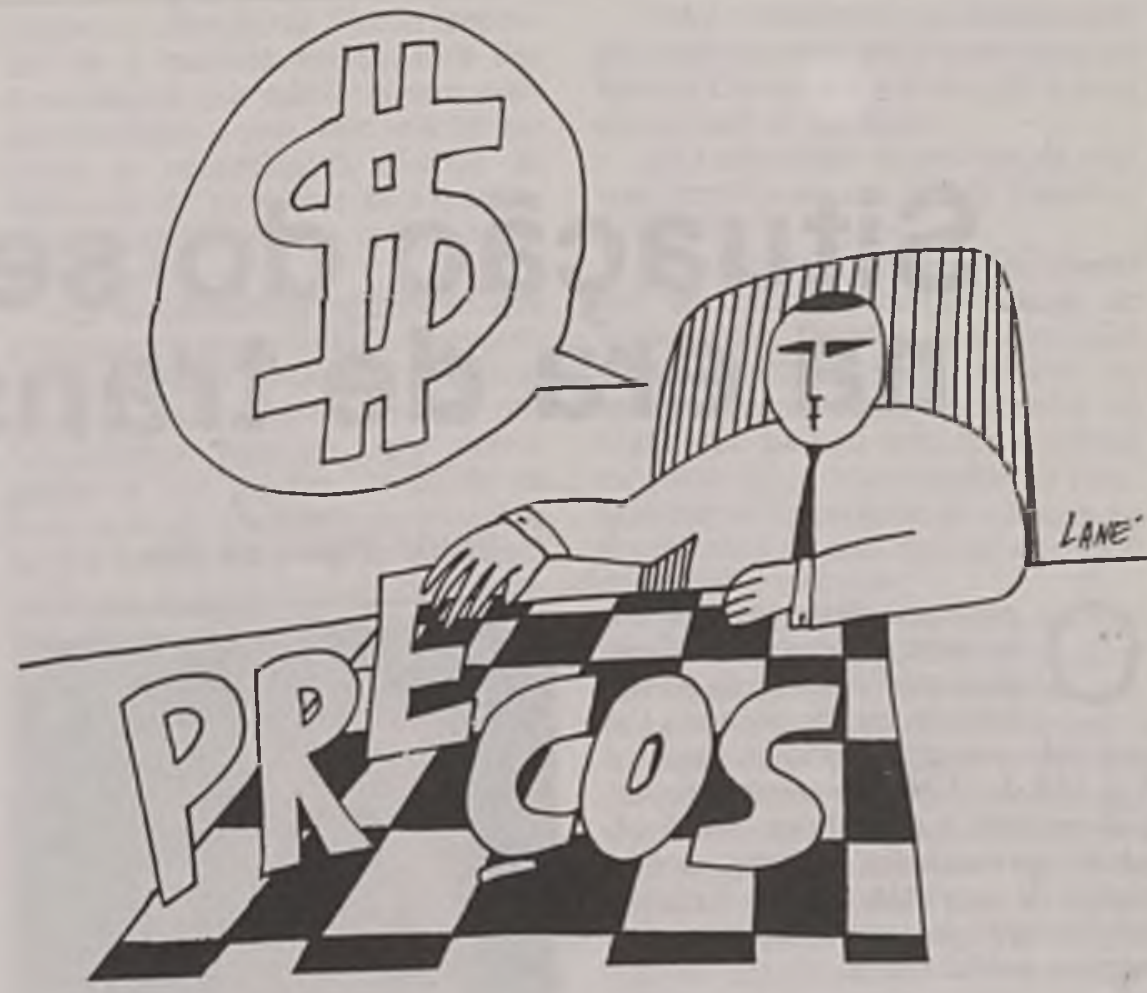

orienta prioridades, afasta privilegios, minimiza disparidades.

Na fixação dos objetivos nacionais e de governo, impóe-se a pessoa do politico-administrador - o estadista. Na elaboração e execuçảo dos programas e projetos de governo, a pessoa do administrador publico tecnoburocrata, da limitaçāo do especialista professoral, ou do apenas prático; alguém eclético, perspicaz, com vivencia tanto do mundo da burocracia pública (defensora da sode), seja qual for sua formação profissional. cas, ao lado do empresário, do sinalguém distanciado da estreiteza do ciedade), quanto do mundo da iniciativa privada (impulsora da socieda-

No campo das decisỏes econômi- dicalista, do lider trabalhista e de tantos outros representantes das forças de produção e de consumo de uma economia de mercado, o administrador público, com o perfil acima e mais: competente na area especifica da Economia mas, sobretudo, na da Administração; sem medo de errar, com o firme proposito de acertar; negociando e conduzindo suas decisões com os preços, com as reivindicaçōes salariais, com os sindicatos livres, com as greves - com tudo, enfim, que expresse e manifeste, naturatmente, o que a sociedade quer, indicando o que é prioritário e o que é realmente possivel de se fazer.

Eis ai o perfil de um novo alquimista - o do mundo moderno!

\section{NOTAS BIBLIOGRÁFICAS}

(1) A Imard, André \& Aubover, Jeannine - Roma e seu Imperio, in Casson, Lionel - Biting the Bullet in Ancient Roman, in periódico bimestral HORIZON,

(2) Casson, Lionel- Biting the Bull. American Heritage Publishing Co., Inc. USA, p. I8. Summer 1976, nol. XVIII. n. 3, American Heritage Publishin

(3) Vollaire - CONTOS, Abril Cultural, (op. cil., 20 vol., p. 239).

(4) Almard, Andre \& A ubover, Jeannin

(5) Ciasson. Lionel Cop cit - $\alpha$ - Caos politico - a culpa dos professores, in Folha de Sào Paulo.

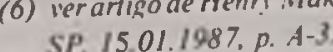

7) Nesse sentido ver Padilha, Tarcisio M. - Filosofia, Ideologia e Realidade brasileira Comp. Edit. Americana, RJ, marco/7I, la ed.

8) - Brasil 1850-1984-Desenvolvimento Financeiro sob um seculo de inflaçăo. Ed. Harper \& Row do Brasil Lida, 1986. SP. pp. 15/16. 